\title{
Cell Cycle Dynamics of the Nuclear Envelope
}

\author{
Roland Foisner \\ Department of Medical Biochemistry, Section of Molecular Cell Biology, Vienna Biocenter, \\ University of Vienna, Dr. Bohrgasse 9, A-1030 Vienna, Austria. \\ E-mail: foisner@abc.univie.ac.at
}

Received May 30, 2002; Revised June 19, 2002; Accepted June 19, 2002; Published March 17, 2003

The nuclear envelope (NE) consists of an inner and an outer membrane, nuclear pore complexes, and the underlying nuclear lamina, a filamentous scaffold structure formed by lamins. The inner membrane is linked to the lamina and chromatin by its integral membrane proteins, such as lamin B receptor (LBR), emerin, and various isoforms of lamina-associated polypeptides (LAP) 1 and 2, which bind lamins and/or chromatin. During mitosis, the NE is disassembled upon phosphorylation of its core components, and the NE is torn apart by a dyneindriven microtubule-dependent mechanism. Nuclear reassembly after sister chromatid separation requires a timely coordinated and dephosphorylationdependent association of lamin-binding proteins and lamins with chromosomal proteins and targeting of membranes to specific sites on chromosomes. Various chromatin-binding domains in lamina proteins, such as the LEM domain, present in all LAP2 isoforms and in emerin, as well as unique regions in lamina proteins and in specific LAP2 isoforms have been implicated in defined steps of NE reformation. Furthermore, novel mechanisms of membrane fusion involving Ran GTPase are just beginning to emerge.

KEY WORDS: BAF, chromatin, chromosomes, higher order chromatin structure, inner nuclear membrane proteins, lamina-associated proteins, lamins, LEM-domain, mitotic phosphorylation, nuclear membrane, nuclear pore complexes, nuclear envelope disassembly, nuclear reassembly, nucleoskeleton, mitotic kinases, Ran GTPase

DOMAINS: cell biology, cell cycle, cell fate and determination, cell cycle (mitosis), cell death, protein transport

\section{COMPONENTS AND POTENTIAL FUNCTIONS OF THE NUCLEAR ENVELOPE}

The eukaryotic nucleus is a complex organelle that contains the chromosomes and is the site of DNA replication, RNA transcription and processing, and ribosome assembly. Nuclear functions 
largely depend on the structural organization of the nucleus and on the formation of a membranous structure, the nuclear envelope (NE), which separates nuclear and cytoplasmic cellular activities. The NE is a double membrane layer composed of two concentric bilayers, the outer nuclear membrane, which is continuous with the endoplasmic reticulum (ER), and the inner nuclear membrane (INM). Outer and inner membranes are separated by a luminal space and are joined at sites, where nuclear pore complexes (NPCs) are inserted into the double membrane system. While the outer membrane is biochemically and functionally similar to the ER and can be considered as a subcompartment of the ER, the inner membrane is clearly distinct in that it contains a specific set of integral membrane proteins[1,2]. The unique protein composition of the INM is thought to be achieved mainly by free diffusion of newly synthesized membrane proteins from the ER through the plane of the outer membrane and the "pore membrane", which connects inner and outer membranes in lateral channels of NPCs, to the inner membrane, where they are retained and stably anchored by specific interactions with intranuclear structures[3,4], such as the lamina and chromatin (reviewed in [5]).

Underneath the inner membrane is a meshwork of nuclear-specific intermediate filaments, termed the nuclear lamina, which provides structural support for chromosomes and maintains nuclear shape and mechanical stability (for review see [6]), spaces NPCs, and is required for key nuclear functions, including DNA replication[7,8.9], and RNA polymerase II-dependent transcription[10]. The core structure of the nuclear lamina is formed by type $\mathrm{V}$ intermediate filament proteins, the lamins, which assemble to a meshwork of tetragonally organized 10-nm filaments underneath the INM (so far only shown in Xenopus oocyte nuclei)[6,11]. In addition to the lamins, a growing number of lamin-binding proteins, mostly integral membrane proteins of the INM[1] are also considered as genuine components of the nuclear lamina. Interestingly, there is strong evidence, that lamins[12,13] and lamin-binding proteins[14,15] are not restricted to the nuclear periphery but exist throughout the nuclear interior. Their molecular structure and functions are, however, still poorly defined[5,6].

The number and complexity of lamins and lamin-binding proteins has increased during metazoan evolution. While Caenorhabditis elegans has only one lamin gene and protein, vertebrates have three lamin genes ( $L M N A, L M N B 1, L M N B 2)$ encoding at least seven distinct isoforms (for review see [16]). Among those, B-type lamins are constitutively expressed in cells throughout development and every cell expresses at least one form of B-type lamins. A-type lamins, comprising lamin $\mathrm{A}$ and its smaller splice variant lamin $\mathrm{C}$ are only expressed in later stages of development and in differentiated cells. Only B-type lamins contain a stable C-terminal farnesyl modification, which is important but not sufficient for targeting and anchoring the protein to the nuclear membrane[17,18,19,20].

To date, the best characterized vertebrate lamin-binding proteins in the INM include: lamin $\mathrm{B}$ receptor (LBR, p58) that has eight transmembrane domains[21], which share extensive homology with sterol reductases[22,23], and interacts with B-type lamins in vivo and in vitro[24,25,26]. Lamina-associated-polypeptide 1 (LAP-1) comprises three alternatively spliced type II integral nuclear membrane proteins (with a single transmembrane spanning region)[27] that interact with A- and B-type lamins[28,29]. Lamina-associated polypeptide 2 (LAP2) (formerly also called thymopoietin) is a family of six alternatively spliced proteins, of which four (LAP2 $\beta, \gamma, \delta$, and $\varepsilon$ ) are type II membrane proteins[30,31]. LAP2 $\beta$ has been found to bind lamin $\mathrm{B}$ in vitro[28] and in vivo[32]. LAP2 $\zeta$ is a truncated version of the LAP2 membrane proteins that has no transmembrane domain, but neither its cellular localization nor its functions are known. LAP $2 \alpha$ is structurally and functionally different from the other isoforms. It shares only the Nterminal 187 amino acids with all the other LAP2 isoforms, but contains a unique C-terminus (506aa) lacking a transmembrane domain[33]. LAP2 $\alpha$ is also unique among the LAP2 isoforms as it is located throughout the nucleus[14] and binds specifically A-type lamins in the nuclear interior[15]. Emerin , a type II inner nuclear membrane protein[34,35], and MAN1, a membrane 
protein containing two transmembrane regions[36], are related to LAP2, as all proteins share a 40-amino-acid-long highly homologous structural motif, the Lamina-associated-polypeptide Emerin MAN1-domain (LEM domain,) in their N-termini, which comprises a helical turn and 2 large parallel $\alpha$-helices connected by a 11 to 12 residue loop[37,38]. Emerin binds both A- and Btype lamins in vitro[39,40,41,42] and its retention in the NE requires A-type lamins[43,44].

In addition to the lamin-binding proteins other integral proteins of the INM have recently been identified in vertebrates, such as nurim containing 5 predicted transmembrane domains and only few hydrophilic residues[45], Unc-84 and LUMA with three to four predicted transmembrane domains[46,47], a Ring Finger Binding Protein (RFBP), which resembles a type IV phospholipid pump[48], and a new family of spectrin repeat containing type II membrane proteins, Myne-1 and Nesprins[49,50]. Interestingly, Myne-1 has been described to contain an interrupted LEM-like motif and to interact with lamin A[50], but more data are needed to show any functional overlap with LEM proteins.

In addition to the nuclear membrane and the nuclear lamina, NPCs are genuine constituents of the NE. NPCs are large and extremely elaborate structures that mediate bidirectional traffic of macromolecules across the nuclear membranes. They are made of a massive symmetrical framework comprising about 50 different proteins and show an eightfold rotational symmetry[51,52]; 50- to 100-nm-long fibers joined at their distal ends by a $\sim 50$-nm ring form a basket like structure extending from the nuclear surface of the core NPCs into the nuclear interior. Nup 153, whose dynamics have been studied fairly well (see below), is a constituent of this nucleoplasmic basket[53]. Two integral membrane proteins have been described in the "nuclear pore membrane": gp210[54,55] and POM 121[56], which may anchor NPCs in the membrane.

The importance of lamina proteins for cell and tissue function has been underlined by several recent findings: functional disruption approaches in Drosophila [57], C. elegans[58], and cultured mammalian cells[59] revealed that B-type lamins are essential for viability. Targeted disruption of A-type lamins in mice caused muscular dystrophy, loss of adipose tissue, and early death[43]. Furthermore, mutations in the $L M N A$ gene or in the gene encoding emerin were linked to heritable human diseases (laminopathies) $[60,61,62,63,64]$. Emerin mutations cause X-linked Emery Dreifuss Muscular Dystrophy (XL-EDMD)[65], mutations in LMNA - an autosomal dominant form of the disease (AD-EDMD)[66], characterized by tendon contractures, wasting and weakness of skeletal muscle, and life threatening cardiac conduction problems. Dominant LMNA mutations were also linked to dilated cardiomyopathy with conduction system disease (DCM-CD)[67], limb girdle muscular dystrophy (LGMD1B)[68], and familial partial lipodystrophy (FPLD)[69,70], homozygous defects in $L M N A$ to autosomal recessive axonal neuropathy (Chariot-Marie-Tooth disorder type 2, AR-CMT2)[71]. Although these findings point to essential functions of lamina proteins, the molecular mechanisms are still subject to speculation, suggesting roles in structural organization of chromatin in the nucleus, in controlling gene expression directly via transcription factors or indirectly by epigenetic mechanisms, and in cell proliferation.

\section{NE DYNAMICS DURING INTERPHASE}

Like cytoplasmic intermediate filaments, the components of the nuclear lamina, including lamins and lamin-binding proteins, are highly resistant against solubilization in buffers containing nonionic detergent and high salt[28,72], leading to the assumption that the lamina is a highly stable, undynamic structure. Expression of GFP-lamin fusions combined with fluorescence recovery after photobleaching (FRAP) analyses revealed a very slow recovery in late G1 and Sphase cells $[13,73,74]$, supporting the notion of a highly stable structure. FRAP analysis of cells expressing labeled NPC protein POM 121 and lamin B revealed that individual NPCs do not 
show independent movements relative to each other, most likely due to their tight attachment to the nuclear lamina[74]. These authors observed movement of NPCs and lamina structures in synchronous waves as if they where part of an elastic network, providing compelling evidence for the existence of a flexible but stable lamina - NPC scaffold that supports the nuclear membrane.

Dynamics of GFP-lamin, however, was significantly higher in early G1 cells, when nuclei grow rapidly[13], suggesting rapid incorporation of new subunits into the growing nuclear lamina. Interestingly, expression of a lamin-binding fragment of LAP2 $\beta$ in growing cells was found to inhibit nuclear lamina growth and inhibited progression of cells into S-phase[75]. These results imply two important mechanisms for nuclear lamina assembly in interphase. Firstly, lamina assembly requires interaction of lamin subunits with lamin-binding proteins in the INM[18], a notion also supported by the inability of lamins to form lamina like structures in vitro. Secondly, lamina growth is essential for establishing a fully functional nucleus allowing DNA replication. This model is in line with earlier studies showing dependence of DNA replication on an intact lamina in in vitro assembled Xenopus oocyte nuclei and in cells $[7,8,9,76]$.

Particularly A-type lamins localize transiently in the nuclear interior during G1 phase[15,77]. Thus, A-type lamins are most likely not directly incorporated into the nuclear lamina, but accumulate first in the nuclear interior, where they may be post-translationally processed and/or modified. Similarly, microinjected lamin A or lamin C were found to first accumulate in nucleoplasmic foci to different extent, before the majority was incorporated into the nuclear lamina[78,79]. At least for newly synthesized lamin A, which is post-translationally modified by $\mathrm{C}$-terminal farnesylation and subsequent proteolytic cleavage of its 15 aa C-terminal residues containing the farnesyl group[20], intranuclear localization may be partially linked to processing and maturation of the protein[80,81], but the molecular mechanisms remain unclear.

Despite the very stable nature of interphase lamina and NE structures, there has to be a steady exchange of subunits in the assembled structure, as dominant negative lamin mutants lacking their amino termini rapidly disrupted endogenous lamina structure when expressed in cells[8,76,82]. In agreement with FRAP studies in GFP-lamin B- and GFP-lamin A-expressing cells, showing higher overall stability of B- vs. A-type lamin structures, A-type lamins are more efficiently and more rapidly disassembled by lamin mutants $[15,82]$.

\section{NE DISASSEMBLY AT THE ONSET OF MITOSIS}

The more complex the NE has become during metazoan development the more efficient ways had to be developed to disassemble the NE. In vertebrates, the disassembly of the NE defines the transition between prophase and prometaphase. In lower multicellular eukaryotes C. elegans and D. melanogaster, the NE is disrupted only partially and/or at later stages of mitosis[16,83], and $\mathrm{NE}$ dynamics can be considered as an intermediate between a closed mitosis with no NE breakdown in yeast and a completely open mitosis in vertebrates. NE breakdown involves the depolymerization of the lamina, the fragmentation and removal of the nuclear membranes from condensing chromatin, and the disassembly of NPCs.

Interestingly, very recent data suggest that microtubules themselves help to efficiently disassemble the NE in vertebrates by literally ripping open the NE[84,85] (see Fig. 1). Highly sophisticated live cell imaging analyses of cells expressing fluorescent GFP-fusion proteins[86], immunofluorescence[87], and electron microscopy[88] revealed that duplicated centrosomes attach to the NE in nuclear invaginations. While previous studies have suggested that the NE ruptures at sites of invaginations due to pushing of microtubules[87], recent studies clearly showed that the NE seemed to be pulled apart at sites distal to the invaginations $[86,88]$. By 


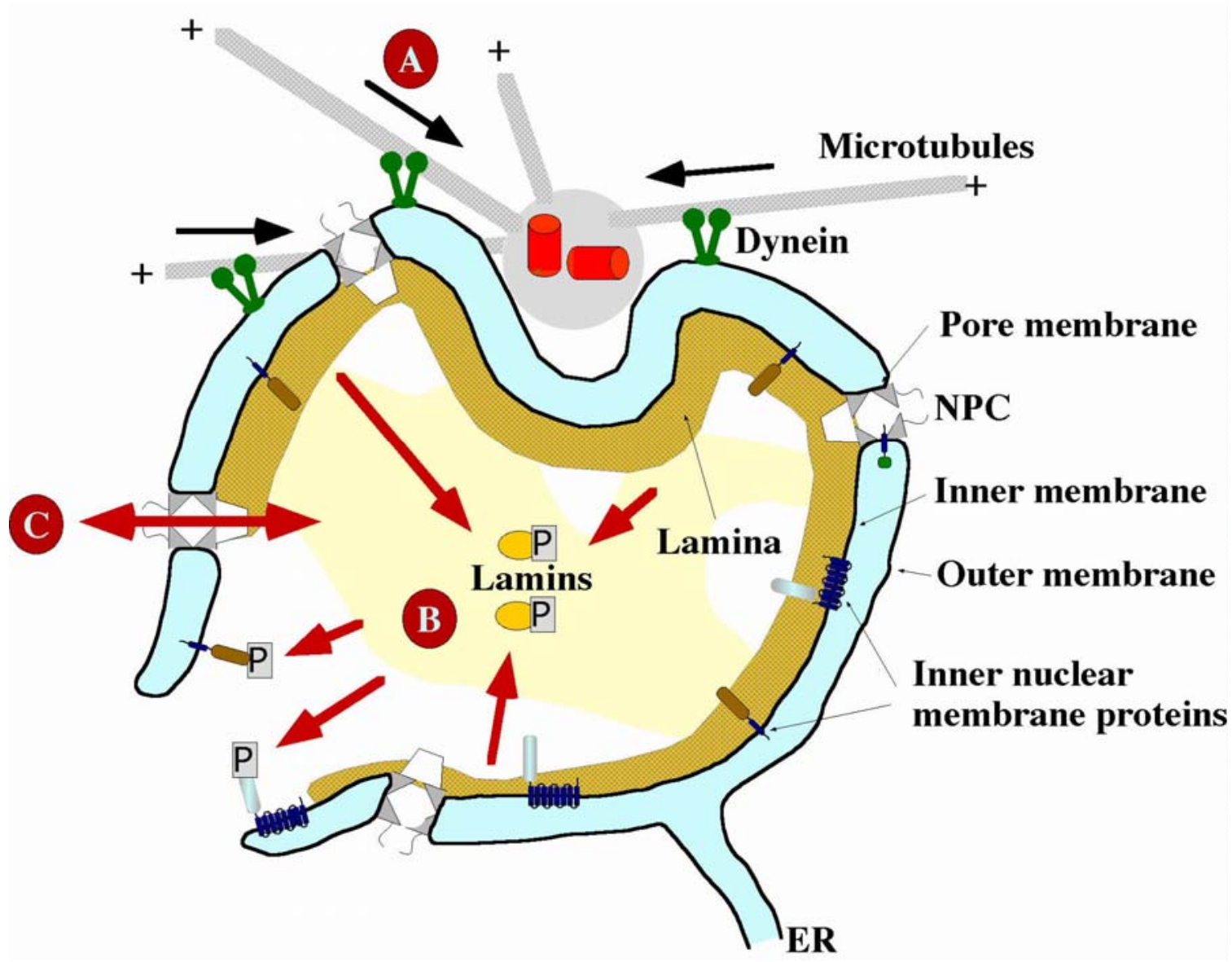

FIGURE 1. Molecular mechanisms of NE disassembly at the onset of mitosis. Arrows denote specific mechanisms known to be involved in NE disassembly. (A): Dynein/dynactin complexes attach at the NE and migrate towards the minus ends of microtubules, assembled from cytoplasmic centrosomes in NE invaginations, and thus, generate a tension that tears the NE open at sites distal to the centrosomes. (B): Lamins and Lamin-binding proteins are phosphorylated by mitotic kinases and dissociate from the lamina and chromatin. (C): NPCs are partially disassembled and become leaky, allowing larger molecules to passively diffuse in or out of the nucleus.

pulling NE components towards the centrosomes, membranes seem to be torn open due to tension. The mechanical force is provided by a minus-end-directed microtubule motor dynein, which is recruited to the NE at late G2 phase[88]. Overexpression of a dynactin component, which usually mediates interaction of dynein with membranes, was found to delay $\mathrm{NE}$ breakdown, probably by interfering with the attachment of endogenous dynein to the membranes. The interaction partner for dynein at the NE remains, however, obscure. It also has to be stated, that the microtubule-dependent NE rupture only facilitates NE breakdown, but is not essential for this process, as nuclear disassembly can also occur in the absence of microtubules.

In view of this novel model for NE disassembly, the contributions of other NE components or other mechanisms to NE breakdown (Fig. 1) appear less clear. The disassembly of NPCs provides one example for another potentially important process in NE breakdown. Using fluorescent dextran dyes, large enough to be excluded from the nucleus, Terasaki et al.[89] could distinguish two phases of nuclear accumulation of dextran during NE breakdown in starfish oocytes, an initial slow uniform increase followed by a massive wave. The slow nuclear translocation of dextran has been attributed to partial NPC disassembly causing leakiness, while the massive wave was correlated with the formation of holes in the NE. This observation suggested that loss of NPC function may precede NE rupturing and may thus allow diffusion of larger protein complexes into the nucleus, which may initiate disassembly. In line with this 
hypothesis, distinct stages of NPC disassembly have been visualized by field emission scanning electron microscopy during mitosis in early Drosophila embryos, including the release of the central transporter and the removal of the cytoplasmic ring subunits followed by removal of star rings[90]. On the other hand, studies in sea urchin embryonic nuclei have shown that blocking NPC function by wheat germ agglutinin prevented NE breakdown, suggesting that active nuclear transport is required for initiation of $\mathrm{NE}$ breakdown[91]. A second possibility, however, is that binding of wheat germ agglutinin to nucleoporins directly blocks NPC disassembly.

In mammalian cells, transport of mitotic cyclin-dependent kinases through NPCs[92] may be required for efficient phosphorylation of lamins and lamin-binding proteins, which then trigger the disassembly of lamins and the dissociation of proteins from chromatin (for review see: $[6,33,93])$. Phosphorylation might be a prerequisite for microtubule-dependent membrane rupture, as phosphorylation-dependent disassembly of lamin structures or dissociation from chromatin may destabilize the NE (Fig. 1). In line with this notion, cells expressing lamin mutants that can not be phosphorylated by mitotic kinases did not efficiently disassemble the NE[94]. Furthermore, lamin A was found to dissociate from the nuclear lamina into the nucleoplasm in early prophase, before it was massively released into the cytoplasm upon NE rupture[87]. This suggests that (phosphorylation-dependent) disassembly of lamin A structures occurs before the NE becomes leaky regardless of the mechanism of NE rupturing.

Phosphorylation of LBR[95,96] and LAP2[14,28] likely triggers the dissociation of membranes from chromatin. B-type lamin subunits often remain associated with membranes due to their C-terminal farnesyl modification, and probably also due to an interaction with LBR throughout mitosis[24]. Immunofluorescence and live cell imaging studies suggested that the nuclear membranes merge into the ER and nuclear membrane proteins diffuse freely throughout the mitotic membrane structures[97,98]. Other studies involving cell lysis and membrane fractionation suggested domain specific vesicularization of the nuclear membrane into different populations of vesicles containing different sets of proteins from the inner nuclear membrane, the pore membrane or the outer nuclear membrane/ER[99,100]. However, in these studies membrane vesicularization and fragmentation might have been caused by cell homogenization (discussed in [101]). Eggs of Xenopus or sea urchin, on the other hand, which contain huge stockpiles of membranes required to support rapid cell divisions, may contain different types of membranes that support nuclear assembly[102,103,104].

\section{POSTMITOTIC REASSEMBLY OF THE NE}

Open mitoses poses problems, because NE and nuclear structure reassembly has to proceed in a tightly regulated manner after chromatid separation, ensuring that the interphase organization of chromatin can be reestablished in daughter nuclei[16].

Numerous studies have shown that the assembly of the NE and the establishment of nuclear and chromatin organization after cell division involves the targeting and assembly of lamins and lamin-binding proteins in a temporally and spatially regulated manner.

\section{Interactions of NE Components with Chromosomes}

In principle, the targeting of NE components to the chromosomal surface could be mediated by any protein that is able to interact with DNA or chromosomal proteins. Lamins can interact with and assemble around chromatin in vitro. This assembly involves their rod domain[105,106] and/or their C-terminal tail domain that binds to core histones[107,108]. In addition, many laminbinding proteins were shown to interact with DNA and/or chromosomal protein. LBR interacted 
directly with DNA[26,109] and bound to human heterochromatin HP1-type chromodomain proteins[110,111] and to histones $\mathrm{H} 3 / \mathrm{H} 4$ in a histone acetylation-dependend manner[112,113]. In cross-linking studies LBR was also found to associate with chromatin-associated HA95, a nuclear protein with high homology to the nuclear A-kinase anchoring protein AKAP95[114]. LAP2 proteins contain several chromatin and/or DNA binding domains, which are either common to all or unique to some isoforms. The LEM domain (amino acids 111-152) in the constant N-terminal region common to all LAP2 proteins (see also Fig. 3), was found by yeast two hybrid assays and by biochemical studies to interact with the chromosomal protein $\underline{B}$ arrier-to- uutointegration Factor (BAF)[115,116]. BAF is an 89-residue, highly conserved protein in multicellular eukaryotes[117] that binds double-stranded DNA without sequence specificity forming nucleoprotein complexes (dodecamers) between DNA molecules[118]. The LEM domain in emerin also bound BAF[39], that in MAN1 has not been experimentally tested yet. Moreover, the $\mathrm{N}$-terminal 50 residues of the LAP2 constant region were found by structural studies to contain a LEM-like motif that bound DNA[37] and an N-terminal 85 residues LAP2 fragment containing the LEM-like motif associated with chromosomes in vitro[32]. In addition to the common Nterminal chromatin binding domains, a DNA binding region has been identified in the LAP2ßspecific region[119], and a chromosome association region in the unique C-terminus of the nucleoskeleton-associated isoform LAP $2 \alpha[120,121]$. Similar to LBR, LAP2 $\beta$ has also been identified by cross-linking experiments to associate with HA95[114]. Thus a complex sequence of interactions between NE components and chromatin is likely involved in the reformation of fully functional daughter nuclei after sister chromatid separation.

\section{Potential Mechanisms of NE Assembly}

In the past years, several labs have investigated the detailed timing of the accumulation of different NE proteins relative to each other at decondensing chromosomes by immunofluorescence and time-lapse microscopic studies in fixed and living cells. By transient expression of GFP-tagged NE proteins Haraguchi et al.[122] could observe membrane targeting to chromosomes 5 min after metaphase-anaphase transition, involving accumulation of LBR and emerin. This was followed by NPC assembly between 5 to 7 min after metaphase-anaphase transition, involving early accumulation of Nup153 and p62 NPC protein. Nuclear import activity could be observed as early as $8 \mathrm{~min}$ after metaphase-anaphase transition, suggesting that nucleartransport-dependent steps may be important for later stages of NE assembly and/or for NE growth. LAP2 $\beta$ was also found to accumulate at chromosomes early[13,28,123] at around the same time as emerin[124]. Finally, we have shown that LAP2 $\alpha$ assembled around chromosomes even earlier than LAP2 $\beta[121]$, suggesting that it is the first protein among the NE/nucleoskeleton components to associate with chromosomes during assembly. Concerning the lamins, recent studies applying GFP tagged lamins have shown that assembly of B- and A-type lamins followed clearly different pathways. B-type lamins associated with chromosomes at early stages of NE reformation, yet LAP2 $\beta$ associated earlier, as it had nearly completely accumulated around chromosomes, when lamin B was detectable on the chromosomal surface[13]. Nevertheless, these 


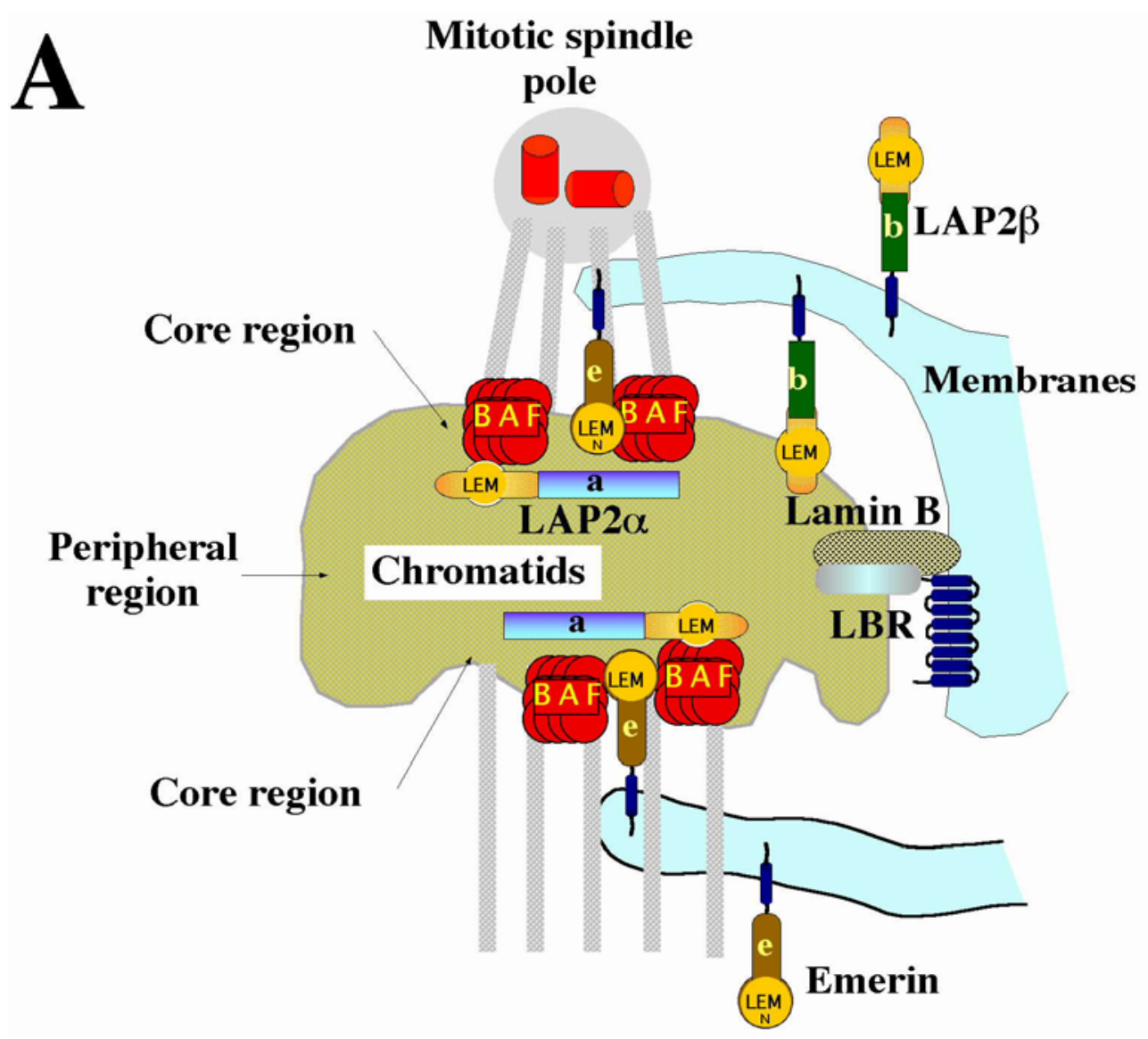

B

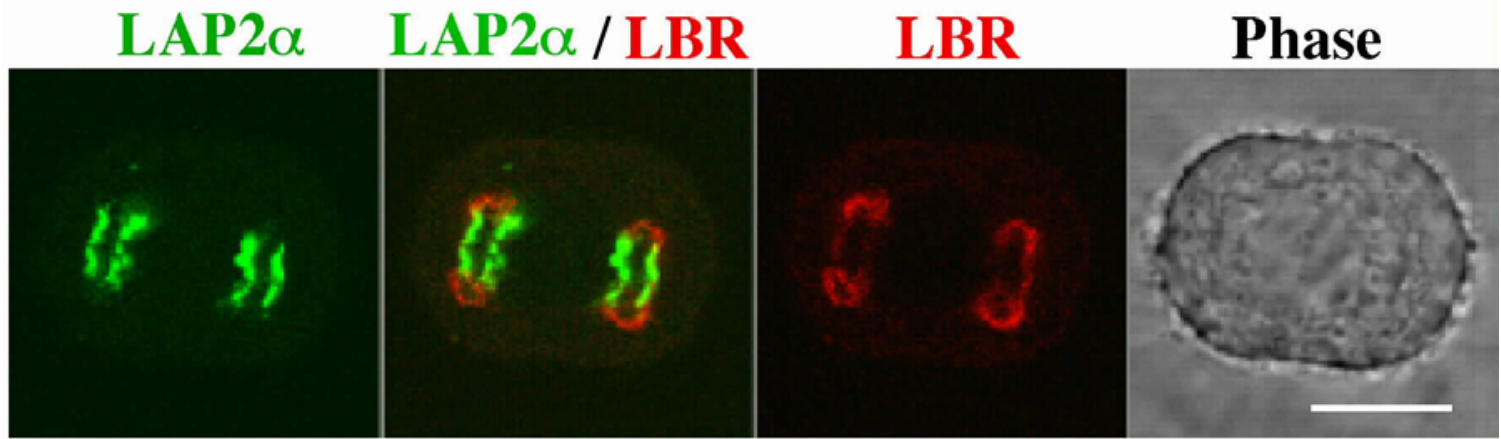

FIGURE 2. Differential attachment sites of proteins at chromosomes during nuclear assembly. (A): Schematic representation of a half-spindle and separated sister chromatids at anaphase, showing preferred attachment of LAP2 $\alpha, \mathrm{BAF}$, and emerin at core regions, and LBR, lamin B and probably LAP2 $\beta$ at peripheral regions of decondensing chromosomes. LEM domains and transmembrane regions of proteins are indicated; LAP $2 \alpha$ is labeled with a, LAP2 $\beta$ with $b$, and emerin with e. (B): Confocal immunofluorescence image of a cell in anaphase expressing YFP-labeled LAP2 $\alpha$ (green) and CFP-labeled LBR (red), and phase contrast image of the same cell. Merge of red and green stain is shown to visualize the different localization of proteins at chromosomes during nuclear assembly in anaphase. Image was kindly provided by Thomas Dechat. Bar represents $10 \mu \mathrm{m}$. 


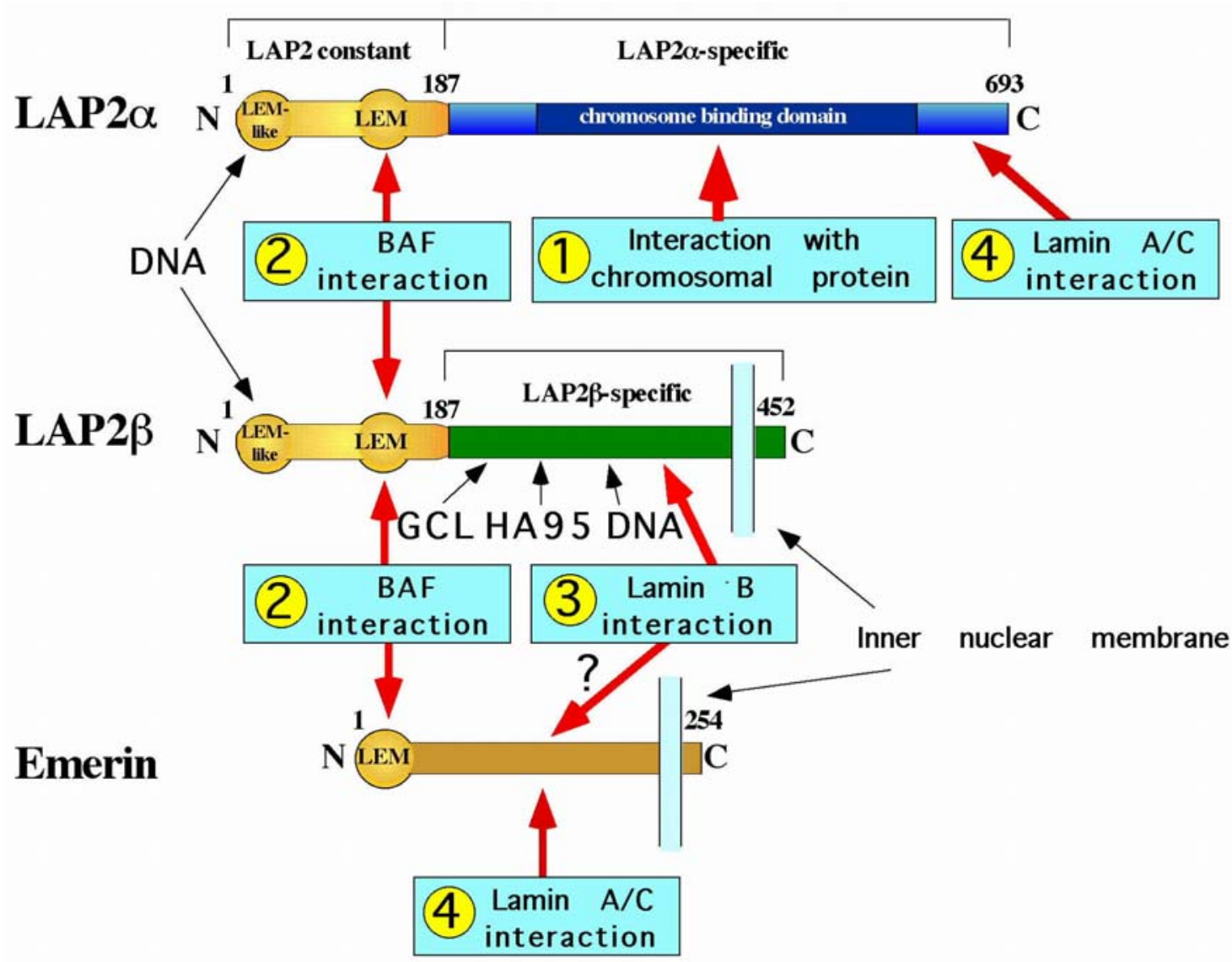

FIGURE 3. Specific interaction of LEM-domain proteins during nuclear assembly. Domains in LAP2 proteins and in emerin are shown. Numbers in boxes indicate the sequence of interactions occurring during NE assembly after mitosis, and red arrows denote interaction domains in the proteins. Black arrows denote interactions, which have not been shown to occur at specific time points of assembly and/or may be important for stabilizing interactions of assembled NE with chromatin in interphase (HA95, DNA) or controlling gene expression (GCL[169]) For details, see text.

studies indicated that a significant fraction of lamin B may access chromosomes directly prior to NE assembly without being imported through NPC. The bulk of lamin A, on the other hand, seemed to translocate through newly assembled NPCs and to accumulate in the nuclear interior rather than the nuclear periphery[13], where they may interact with intranuclear LAP2 $\alpha$ structures in late telophase/G1 phase[14,15]. Thus, the order of assembly of these proteins may be: LAP2 $\alpha$, followed by membrane proteins LAP $2 \beta$, LBR, and emerin, and the NPC proteins NUP 153 and POM 121, followed by lamin B, followed by lamin A.

Another intriguing difference in the dynamic behavior of NE proteins during nuclear assembly was observed in regard to the sites, where proteins associate with chromosomes (Fig. 2). LAP $2 \alpha$ accumulated at "core regions" of the bulk of decondensing chromosomes, which are the regions next to the spindle pole- and midspindle areas[5,14] (Fig. 2B), emerin was first seen at more peripheral sites but accumulated then also at the core regions[122,125], when also a subfraction of lamin $\mathrm{C}$ was detectable there (our unpublished observation). LAP2 $\beta$, lamin B, and particularly LBR accumulated initially at the peripheral chromosomal regions before they formed a continuous rim around the decondensed chromatin[13,97,122,124,125]. This strongly suggested that the chromosome association of these different sets of proteins involves different mechanisms.

The different behavior of LAP2 $\alpha$ and LBR can be easily explained by their interactions with different proteins on chromosomes, such as HP1 and histones for LBR vs. BAF for LAP2 $\alpha$ (see 
above). The different dynamics of LAP $2 \alpha, \mathrm{LAP} 2 \beta$, and emerin in regard to timing and initial site of chromosome association seem, however, less obvious, as all proteins share the LEM domain which mediates interaction with chromosomal BAF.

Several recent observations might help to explain this phenomenon. Firstly, we could show, that the association of LAP $2 \alpha$ with chromosomes at early stages of assembly, required the Cterminal chromatin binding domain that is unique for LAP $2 \alpha$, while the N-terminal LEM-domain was dispensable for this interaction[121] (Fig. 3). Secondly, fragments that contained the LEM domain but lacked the $\alpha$-specific chromatin-binding region did not associate with chromosomes in vivo and in vitro[120,121]. Thirdly, in vitro nuclear assembly assays showed that initial binding of full length LAP $2 \alpha$ is required for membrane assembly around chromosomes, while chromosome binding fragments of LAP $2 \alpha$ lacking the LEM domain inhibited assembly[120]. Thus one can envisage the following model for the initial stages of assembly (Fig. 3): LAP2 $\alpha$ associates first with chromosomes via its C-terminus and this interaction does not depend on or involve the $\mathrm{N}$-terminal LEM domain. This association may trigger conformational changes on the chromosomal surface and/or target cytoplasmic BAF to the chromosomes and/or induce posttranslational modification of BAF or other chromosomal proteins, thus allowing interaction of the LEM domain with BAF. We propose that LAP2 $\beta$ and emerin are then recruited to "active" BAF by their LEM domains and form membrane structures around the chromosomal surface. This model is supported by three recent findings. Firstly, BAF localized to the same core regions on chromosomes, where LAP $2 \alpha$ accumulated[125]. Secondly, expression of a mutant BAF that did not bind to the LEM domain and to DNA and failed to localize at core domains inhibited assembly of emerin, LAP $2 \beta$, and lamin A, but not lamin B, at the NE[125]. Unfortunately, LAP2 $\alpha$ has not been tested yet in these cells. Thirdly, addition of BAF to in vitro Xenopus nuclear assembly reactions deregulated chromatin condensation, causing enhanced chromatin decondensation at low concentrations and a block of decondensation and nuclear assembly at higher concentrations[126].

\section{Contribution of Individual Proteins to NE Assembly}

NE assembly includes a complex, highly regulated, and timely coordinated sequence of interactions. To analyze the specific contributions and importance of different NE components and their interactions for nuclear assembly, several labs have expressed mutants in cells or have added mutant proteins to Xenopus and mammalian in vitro nuclear assembly assays, or have immunodepleted specific NE proteins from in vitro assembly extracts. As mentioned above, addition of wild type BAF to Xenopus egg extracts[126], or expression of BAF mutants lacking emerin- and DNA binding in cells[125] interfered with NE assembly. Similarly, addition of LAP $2 \alpha$ mutants missing the LEM domain to mammalian nuclear assembly reactions[120], or addition of N-terminal LAP2 constant region to Xenopus egg extracts[127] inhibited assembly of nuclear membranes. However, expression of the LAP2 constant region in cells had no effect[120,121]. Immunodepletion of LBR from membrane vesicles of avian cells inhibited binding to chromosomes[128] and addition of LBR antibodies to sea urchin egg extracts affected nuclear assembly[129].

Interestingly, studies in the Xenopus nuclear assembly system have revealed two distinct vesicle populations[104], which contain different sets of membrane proteins, and recruitment of these vesicles in an ordered fashion was essential for nuclear membrane assembly[103]. This, however, may be a specific feature in oocytes that contain huge stockpiles of membranes. Taking together, interfering with functions of most NE/chromatin proteins significantly affects NE assembly, suggesting that all these proteins are essential for nuclear assembly during a specific stage or in a specific cell system. 
The contribution of lamins to NE assembly has been controversial[130]. While immunodepletion of lamins from Xenopus in vitro nuclear assembly extracts did not inhibit NE formation[9,131], other studies using Drosophila, mammalian, and Xenopus extracts showed that immunoadsorption of lamins inhibited NE assembly[132,133,134]. The different results were most likely caused by the different efficiencies in depleting and/or deactivating lamins by antibodies or might be attributed to the continued presence of aggregated lamins in the assembly reaction. Lopez-Soler et al. have recently added a peptide representing the C-terminal domain of Xenopus lamin B3, which inhibited lamin interactions and lamina assembly, to nuclear assembly reactions and found inhibition of membrane assembly around chromatin[135]. Conversely, inhibition of lamin B assembly in HeLa cells by inhibiting its protein phosphatase 1 (PP1)dependent dephosphorylation did not block the assembly of the nuclear membrane and of lamin A, but induced apoptosis in G1 phase[136,137]. Thus, although a polymerized lamina (containing lamin B) is not important for assembly of the nuclear membrane, it is essential for cell viability in interphase, as also shown by functional disruption of B-type lamins in Drosophila[57] and C. elegans[58]. Taking all these experiments together, one may conclude that lamins may be important for nuclear membrane assembly, a typical lamina however, is not.

\section{Assembly of NPCs}

As for NPC assembly, basket-associated Nup 153 and the pore membrane protein POM 121 are the first NPC proteins to associate with chromatin, whereas pore membrane protein gp210 and Tpr, which associates with the nuclear surface of NPCs, accumulate later[123]. The sequential recruitment of NPC proteins may reflect the appearance of discrete intermediates in the assembly of mature NPCs in vitro[138]. Thus, binding of Nup 153 or POM 121 to chromatin could define sites of NPC assembly, which subsequently may recruit additional hierarchies of NPC proteins. In line with such a hypothesis, NPCs assembled in the absence of Nup 153 from immunodepleted extracts lacked several basket structures, were not stably anchored in the NE, and were defective in the importin-mediated transport[139]. In other studies Nup 153 was found to interact with lamin LIII, and Nup153 assembly at chromosomes was dependent on the formation of a lamina[140]. Thus, Nup153 may be important for linking the NPC to the lamina. Strikingly, however, Nup153 fluorescence recovered much faster than those of other NPC proteins[74], indicating that Nup153 undergoes a rapid exchange between intranuclear and NPC associated pools. Thus Nup 153 may have different roles during assembly and in mature NPC, where it may mainly be involved in transport. The presence of zinc-finger motifs in Nup153 that may mediate DNA interaction[141] may facilitate its early association with chromosomes during nuclear reassembly in a membrane-independent manner.

\section{REGULATION OF NE DYNAMICS}

\section{Phosphorylation-Dependent Mechanisms}

The rapid disassembly of the NE at the onset of mitosis is driven by mitotic phosphorylation of lamins[142], LAP1 and LAP2[14,28,33], probably LBR[95,96,109,143,144], NPC proteins[145,146], and most likely other NE components. For lamins, p34 ${ }^{c d c 2}$ kinase, has been identified as the most prominent mitotic kinase involved in the disassembly of the lamina in vivo and in vitro[94,147,148,149,150], and ectopically expressed lamin A with mutations in the $c d c 2$ phosphorylation sites failed to be disassembled during mitosis. There are also other kinases 
known to be involved[151], such as PKC $[152,153]$. Membrane proteins are most likely also targets for mitotic $\mathrm{p} 34^{c d c 2}$ kinase, but this has not been confirmed by mutating the respective phosphorylation sites in the proteins and analyzing the effect on assembly/disassembly in vivo. LBR was also shown to be phosphorylated by a serine/arginine kinase[95,144] that modulated interaction of LBR with other nuclear proteins.

Nuclear reassembly requires phosphatase activity and, at least for B-type lamins, has been shown to involve phosphatase PP1[154]. PP1 is targeted to the NE by a membrane protein of the ER and the NE, protein A-kinase anchoring protein (AKAP149)[155]. PP1 recruitment from chromosomes to membranes at the nuclear periphery in telophase is a prerequisite for assembly of B-type lamins. Inhibition of PP1 association with AKAP149 by a peptide containing the PP1 binding domain of AKAP149 resulted in lack of assembly of B-type lamins and apoptosis[136,137]. These findings suggest that lamin B assembly is dependent on the presence of membranes at the chromatin surface and confirms time-lapse microscopic studies showing that lamin B assembly starts after LAP2 $\beta$-containing membranes have bound to chromosomes[13]. Interestingly, assembly of A-type lamins was not effected by the peptide, supporting other studies which show different pathways of assembly of A- and B-type lamins after mitosis[13,15].

\section{Mechanisms Involved in Later Stages of NE Assembly}

While early stages of NE assembly, such as membrane targeting to chromosomes, are energy independent and may mostly depend on protein dephosphorylation, the events causing membrane fusion are less well known. GTP hydrolysis was known to be required for vesicle fusion for several years[156,157], but only more recent studies in Xenopus egg extracts have shed light on the molecules involved. Both Ran GTPase activity and RCC1, the nucleotide exchange factor for Ran, have been found to be essential for extensive membrane fusion on the chromatin surface[158]. As beads coated with Ran-GDP were also surrounded by a membrane containing functional NPC in a RCC1- or GTPase activity-dependent manner, this process seems to be independent of chromatin[159]. It is not known, however, how membranes were targeted to the bead's surface, whether a stable nuclear lamina assembled, and whether INM proteins were accumulated in these studies. The involvement of Ran GTPase in NE assembly has also been confirmed in vivo by RNAi mediated downregulation of Ran or RCC1 in C. elegans embryos[160].

Intriguingly, importin- $\beta$, a Ran effector in nucleocytoplasmic transport[161,162], has been suggested to mediate Ran-dependent NE assembly in an importin- $\alpha$-independent manner[163]. In this model, importin- $\beta$ interacting with FxFG repeat containing nucleoporins may be targeted to chromosomes due to its interaction with Ran GTP, which is generated by chromosome bound GTP/GDP exchange factor RCC1. Since binding of importin- $\beta$ to Ran-GTP decreases its affinity for nucleoporins, they may be released locally at the surface of chromosomes and facilitate NPC and NE assembly. Since Ran-regulated interactions of importin- $\beta$ control also nuclear transport[161] and mitotic spindle assembly[164,165,166], changes in localization, concentration, and interactions of RanGTP/RanGDP and importin- $\beta$ may help coordinate spindle assembly/disassembly with reassembly of the NE and with initiation of nucleocytoplasmic transport. The potential function of importin- $\beta$ in NE assembly was also confirmed in Drosophila expressing an importin- $\beta$ mutant that lacked RanGTP binding activity[167].

The molecular components involved in membrane fusion are just beginning to be discovered. These may include both components previously known to be involved in fusion of Golgi and ER membranes, such as AAA-ATPase p97-p47 adaptor complexes during NE growth, and complexes not previously implicated in membrane fusions, such as p97/Ufd1-Np14 adaptor 
complexes. Interestingly, the latter complexes have been implicated in early $\mathrm{NE}$ fusion events[168]. Assuming that ER and INM are interdispersed in mitotic stage, different adaptors responsible for fusion of ER and NE membranes would ensure that both membrane systems, ER and NM, are processed in different ways upon exit from mitosis. It is intriguing to speculate that INM proteins could be involved in such a mechanism by recruiting specific adaptor-p97 complexes.

\section{ACKNOWLEDGEMENTS}

I want to thank Thomas Dechat, Vienna Biocenter, for providing immunofluorescence images in Fig. 2. I am also grateful to Sylvia Vlcek, Vienna Biocenter, for her valuable comments on the manuscript. Work in the author's laboratory was supported by grants from the Austrian Science Research Fund (FWF) No. P15312, from the Jubiläumsfonds of the Austrian National Bank, and from the "Österreichische Muskelforschung" to RF.

\section{REFERENCES}

1. $\quad$ Foisner, R. (2001) Inner nuclear membrane proteins and the nuclear lamina. J. Cell Sci. 114, 3791-3792.

2. Gerace, L. and Foisner, R. (1994) Integral membrane proteins and dynamic organization of the nuclear envelope. Trends Cell Biol. 4, 127-131.

3. Wu, W., Lin, F., and Worman, H.J. (2002) Intracellular trafficking of MAN1, an integral protein of the nuclear envelope inner membrane. J. Cell Sci. 115, 1361-1371.

4. Soullam, B. and Worman, H.J. (1995) Signals and structural features involved in integral membrane protein targeting to the inner nuclear membrane. J. Cell Biol. 130, 15-27.

5. Vlcek, S., Dechat, T., and Foisner, R. (2001) Nuclear envelope and nuclear matrix: interactions and dynamics. Cell. Mol. Life Sci. 58, 1758-1765.

6. Goldman, R.D., Gruenbaum, Y., Moir, R.D., Shumaker, D.K., and Spann, T.P. (2002) Nuclear lamins: building blocks of nuclear architecture. Genes Dev. 16, 533-547.

7. Ellis, D.J., Jenkins, H., Whitfield, W.G., and Hutchison, C.J. (1997) GST-lamin fusion proteins act as dominant negative mutants in Xenopus egg extract and reveal the function of the lamina in DNA replication. J. Cell Sci. 110, 2507-2518.

8. Moir, R.D., Spann, T.P., Herrmann, H., and Goldman, R.D. (2000) Disruption of nuclear lamin organization blocks the elongation phase of DNA replication. J. Cell Biol. 149, 1179-1192.

9. Newport, J.W., Wilson, K.L., and Dunphy, W.G. (1990) A lamin-independent pathway for nuclear envelope assembly. J. Cell Biol. 111, 2247-2259.

10. Spann, T.P., Goldman, A.E., Wang, C., Huang, S., and Goldman, R.D. (2002) Alteration of nuclear lamin organization inhibits RNA polymerase II-dependent transcription. J. Cell Biol. 156, 603-608.

11. Stuurman, N., Heins, S., and Aebi, U. (1998) Nuclear lamins: their structure, assembly, and interactions. $J$. Struct. Biol. 122, 42-66.

12. Hozak, P., Sasseville, A.M., Raymond, Y., and Cook, P.R. (1995) Lamin proteins form an internal nucleoskeleton as well as a peripheral lamina in human cells. J. Cell Sci. 108, 635-644.

13. Moir, R.D., Yoon, M., Khuon, S., and Goldman, R.D. (2000) Nuclear lamins A and B1: different pathways of assembly during nuclear envelope formation in living cells. J. Cell Biol. 151, 1155-1168.

14. Dechat, T., Gotzmann, J., Stockinger, A., Harris, C.A., Talle, M.A., Siekierka, J.J., and Foisner, R. (1998) Detergent-salt resistance of LAP2alpha in interphase nuclei and phosphorylation-dependent association with chromosomes early in nuclear assembly implies functions in nuclear structure dynamics. EMBO J. 17, 4887-4902.

15. Dechat, T., Korbei, B., Vaughan, O.A., Vlcek, S., Hutchison, C.J., and Foisner, R. (2000) Laminaassociated polypeptide 2alpha binds intranuclear A-type lamins. J. Cell Sci. 113, 3473-3484.

16. Cohen, M., Lee, K.K., Wilson, K.L., and Gruenbaum, Y. (2001) Transcriptional repression, apoptosis, human disease and the functional evolution of the nuclear lamina. Trends Biochem. Sci. 26, 41-47.

17. Hennekes, H. and Nigg, E.A. (1994) The role of isoprenylation in membrane attachment of nuclear lamins. 
A single point mutation prevents proteolytic cleavage of the lamin A precursor and confers membrane binding properties. J. Cell Sci. 107, 1019-1029.

18. Hutchison, C.J., Alvarez-Reyes, M., and Vaughan, O.A. (2001) Lamins in disease: why do ubiquitously expressed nuclear envelope proteins give rise to tissue-specific disease phenotypes? J. Cell Sci. 114, 9-19.

19. Mical, T.I. and Monteiro, M.J. (1998) The role of sequences unique to nuclear intermediate filaments in the targeting and assembly of human lamin B: evidence for lack of interaction of lamin B with its putative receptor. J. Cell Sci. 111, 3471-3485.

20. Moir, R.D., Spann, T.P., and Goldman, R.D. (1995) The dynamic properties and possible functions of nuclear lamins. Int. Rev. Cytol. 141-182.

21. Worman, H.J., Evans, C.D., and Blobel, G. (1990) The lamin B receptor of the nuclear envelope inner membrane: a polytopic protein with eight potential transmembrane domains. J. Cell Biol. 111, 1535-1542.

22. Holmer, L., Pezhman, A., and Worman, H.J. (1998) The human lamin B receptor/sterol reductase multigene family. Genomics 54, 469-476.

23. Silve, S., Dupuy, P.H., Ferrara, P., and Loison, G. (1998) Human lamin B receptor exhibits sterol C14reductase activity in Saccharomyces cerevisiae. Biochim. Biophys. Acta 1392, 233-244.

24. Meier, J. and Georgatos, S.D. (1994) Type B lamins remain associated with the integral nuclear envelope protein p58 during mitosis: implications for nuclear reassembly. EMBO J. 13, 1888-1898.

25. Simos, G. and Georgatos, S.D. (1992) The inner nuclear membrane protein p58 associates in vivo with a p58 kinase and the nuclear lamins. EMBO J. 11, 4027-4036.

26. Ye, Q. and Worman, H.J. (1994) Primary structure analysis and lamin B and DNA binding of human LBR, an integral protein of the nuclear envelope inner membrane. J. Biol. Chem. 269, 11306-11311.

27. Martin, L., Crimaudo, C., and Gerace, L. (1995) cDNA cloning and characterization of lamina-associated polypeptide 1C (LAP1C), an integral protein of the inner nuclear membrane. J. Biol. Chem. 270, 88228828.

28. Foisner, R. and Gerace, L. (1993) Integral membrane proteins of the nuclear envelope interact with lamins and chromosomes, and binding is modulated by mitotic phosphorylation. Cell 73, 1267-1279.

29. Powell, L. and Burke, B. (1990) Internuclear exchange of an inner nuclear membrane protein (p55) in heterokaryons: in vivo evidence for the interaction of p55 with the nuclear lamina. J. Cell Biol. 111, 22252234.

30. Berger, R., Theodor, L., Shoham, J., Gokkel, E., Brok-Simoni, F., Avraham, K.B., Copeland, N.G., Jenkins, N.A., Rechavi, G., and Simon, A.J. (1996) The characterization and localization of the mouse thymopoietin/lamina- associated polypeptide 2 gene and its alternatively spliced products. Genome Res. 6, 361-370.

31. Harris, C.A., Andryuk, P.J., Cline, S., Chan, H.K., Natarajan, A., Siekierka, J.J., and Goldstein, G. (1994) Three distinct human thymopoietins are derived from alternatively spliced mRNAs. Proc. Natl. Acad. Sci. U. S. A. 91, 6283-6287.

32. Furukawa, K., Fritze, C.E., and Gerace, L. (1998) The major nuclear envelope targeting domain of LAP2 coincides with its lamin binding region but is distinct from its chromatin interaction domain. J. Biol. Chem. 273, 4213-4219.

33. Dechat, T., Vlcek, S., and Foisner, R. (2000) Review: lamina-associated polypeptide 2 isoforms and related proteins in cell cycle-dependent nuclear structure dynamics. J. Struct. Biol. 129, 335-345.

34. Manilal, S., thi Man, N., Sewry, C.A., and Morris, G.E. (1996) The Emery-Dreifuss muscular dystrophy protein, emerin, is a nuclear membrane protein. Hum. Mol. Genet. 5, 801-808.

35. Östlund, C., Ellenberg, J., Hallberg, E., Lippincott-Schwartz, J., and Worman, H.J. (1999) Intracellular trafficking of emerin, the Emery-Dreifuss muscular dystrophy protein. J. Cell Sci. 112, 1709-1719.

36. Lin, F., Blake, D.L., Callebaut, I., Skerjanc, I.S., Holmer, L., McBurney, M.W., Paulin-Levasseur, M., and Worman, H.J. (2000) MAN1, an inner nuclear membrane protein that shares the LEM domain with laminaassociated polypeptide 2 and emerin. J. Biol. Chem. 275, 4840-4847.

37. Cai, M., Huang, Y., Ghirlando, R., Wilson, K.L., Craigie, R., and Clore, G.M. (2001) Solution structure of the constant region of nuclear envelope protein LAP2 reveals two LEM-domain structures: one binds BAF and the other binds DNA. EMBO J. 20, 4399-4407.

38. Laguri, C., Gilquin, B., Wolff, N., Romi-Lebrun, R., Courchay, K., Callebaut, I., Worman, H.J., and ZinnJustin, S. (2001) Structural characterization of the lem motif common to three human inner nuclear membrane proteins. Structure (Camb) 9, 503-511.

39. Lee, K.K., Haraguchi, T., Lee, R.S., Koujin, T., Hiraoka, Y., and Wilson, K.L. (2001) Distinct functional domains in emerin bind lamin A and DNA-bridging protein BAF. J. Cell Sci. 114, 4567-4573.

40. Clements, L., Manilal, S., Love, D.R., and Morris, G.E. (2000) Direct interaction between emerin and lamin A. Biochem. Biophys. Res. Commun. 267, 709-714.

41. Fairley, E.A., Kendrick-Jones, J., and Ellis, J.A. (1999) The Emery-Dreifuss muscular dystrophy phenotype arises from aberrant targeting and binding of emerin at the inner nuclear membrane. J. Cell Sci. 112, 25712582.

42. Sakaki, M., Koike, H., Takahashi, N., Sasagawa, N., Tomioka, S., Arahata, K., and Ishiura, S. (2001) 
Interaction between emerin and nuclear lamins. J. Biochem. (Tokyo) 129, 321-327.

43. Sullivan, T., Escalante-Alcalde, D., Bhatt, H., Anver, M., Bhat, N., Nagashima, K., Stewart, C.L., and Burke, B. (1999) Loss of A-type lamin expression compromises nuclear envelope integrity leading to muscular dystrophy. J. Cell Biol. 147, 913-920.

44. Vaughan, O.A., MAlvarez-Reyes, M., Bridger, J.M., Broers, L.V., Ramaekers, F.C.S., Wehnert, M., Morris, G., Whitfield, W.G.F., and Hutchison, C.J. (2001) Both emerin and lamin C depend on lamin A for localization at the nuclear envelope. J. Cell Sci. 114, 2577-2590.

45. Rolls, M.M., Stein, P.A., Taylor, S.S., Ha, E., McKeon, F., and Rapoport, T.A. (1999) A visual screen of a GFP-fusion library identifies a new type of nuclear envelope membrane protein. J. Cell Biol. 146, $29-44$.

46. Dreger, M., Bengtsson, L., Schoneberg, T., Otto, H., and Hucho, F. (2001) Nuclear envelope proteomics: novel integral membrane proteins of the inner nuclear membrane. Proc. Natl. Acad. Sci. U. S. A. 98, 1194311948.

47. Lee, K.K., Starr, D., Cohen, M., Liu, J., Han, M., Wilson, K.L., and Gruenbaum, Y. (2002) Lamindependent localization of UNC-84, a protein required for nuclear migration in Caenorhabditis elegans. Mol. Biol. Cell 13, 892-901.

48. Mansharamani, M., Hewetson, A., and Chilton, B.S. (2001) Cloning and characterization of an atypical Type IV P-type ATPase that binds to the RING motif of RUSH transcription factors. J. Biol. Chem. 276, 3641-3649.

49. Zhang, Q., Skepper, J.N., Yang, F., Davies, J.D., Hegyi, L., Roberts, R.G., Weissberg, P.L., Ellis, J.A., and Shanahan, C.M. (2001) Nesprins: a novel family of spectrin-repeat-containing proteins that localize to the nuclear membrane in multiple tissues. J. Cell Sci. 114, 4485-4498.

50. Mislow, J.M., Kim, M.S., Davis, D.B., and McNally, E.M. (2002) Myne-1, a spectrin repeat transmembrane protein of the myocyte inner nuclear membrane, interacts with lamin A/C. J. Cell Sci. 115, 61-70.

51. Stoffler, D., Fahrenkrog, B., and Aebi, U. (1999) The nuclear pore complex: from molecular architecture to functional dynamics. Curr. Opin. Cell Biol. 11, 391-401.

52. Allen, T.D., Cronshaw, J.M., Bagley, S., Kiseleva, E., and Goldberg, M.W. (2000) The nuclear pore complex: mediator of translocation between nucleus and cytoplasm. J. Cell Sci. 113, 1651-1659.

53. Cordes, V.C., Reidenbach, S., Kohler, A., Stuurman, N., van Driel, R., and Franke, W.W. (1993) Intranuclear filaments containing a nuclear pore complex protein. J. Cell Biol. 123, 1333-1344.

54. Wozniak, R.W., Bartnik, E., and Blobel, G. (1989) Primary structure analysis of an integral membrane glycoprotein of the nuclear pore. J. Cell Biol. 108, 2083-2092.

55. Greber, U.F., Senior, A., and Gerace, L. (1990) A major glycoprotein of the nuclear pore complex is a membrane-spanning polypeptide with a large lumenal domain and a small cytoplasmic tail. EMBO J. 9, 1495-1502.

56. Hallberg, E., Wozniak, R.W., and Blobel, G. (1993) An integral membrane protein of the pore membrane domain of the nuclear envelope contains a nucleoporin-like region. J. Cell Biol. 122, 513-521.

57. Lenz-Bohme, B., Wismar, J., Fuchs, S., Reifegerste, R., Buchner, E., Betz, H., and Schmitt, B. (1997) Insertional mutation of the Drosophila nuclear lamin Dm0 gene results in defective nuclear envelopes, clustering of nuclear pore complexes, and accumulation of annulate lamellae. J. Cell Biol. 137, 1001-1016.

58. Liu, J., Ben-Shahar, T.R., Riemer, D., Treinin, M., Spann, P., Weber, K., Fire, A., and Gruenbaum, Y. (2000) Essential roles for Caenorhabditis elegans lamin gene in nuclear organization, cell cycle progression, and spatial organization of nuclear pore complexes. Mol. Biol. Cell 11, 3937-3947.

59. Harborth, J., Elbashir, S.M., Bechert, K., Tuschl, T., and Weber, K. (2001) Identification of essential genes in cultured mammalian cells using small interfering RNAs. J. Cell Sci. 114, 4557-4565.

60. Hegele, R.A. (2001) Molecular basis of partial lipodystrophy and prospects for therapy. Trends Mol. Med. 7, 121-126.

61. Bonne, G., Mercuri, E., Muchir, A., Urtizberea, A., Becane, H.M., Recan, D., Merlini, L., Wehnert, M., Boor, R., Reuner, U., Vorgerd, M., Wicklein, E.M., Eymard, B., Duboc, D., Penisson-Besnier, I., Cuisset, J.M., Ferrer, X., Desguerre, I., Lacombe, D., Bushby, K., Pollitt, C., Toniolo, D., Fardeau, M., Schwartz, K., and Muntoni, F. (2000) Clinical and molecular genetic spectrum of autosomal dominant EmeryDreifuss muscular dystrophy due to mutations of the lamin A/C gene. Ann. Neurol. 48, 170-180.

62. Morris, G.E. (2001) The role of the nuclear envelope in Emery-Dreifuss muscular dystrophy. Trends Mol. Med. 7, 572-577.

63. Mounkes, L.C., Burke, B., and Stewart, C.L. (2001) The A-type lamins: nuclear structural proteins as a focus for muscular dystrophy and cardiovascular diseases. Trends Cardiovasc. Med. 11, 280-285.

64. Wilson, K.L., Zastrow, M.S., and Lee, K.K. (2001) Lamins and disease: insights into nuclear infrastructure. Cell 104, 647-650.

65. Bione, S., Maestrini, E., Rivella, S., Mancini, M., Regis, S., Romeo, G., and Toniolo, D. (1994) Identification of a novel X-linked gene responsible for Emery-Dreifuss muscular dystrophy. Nat. Genet. 8, 323-327.

66. Bonne, G., Di Barletta, M.R., Varnous, S., Becane, H.M., Hammouda, E.H., Merlini, L., Muntoni, F., Greenberg, C.R., Gary, F., Urtizberea, J.A., Duboc, D., Fardeau, M., Toniolo, D., and Schwartz, K. (1999) 
Mutations in the gene encoding lamin A/C cause autosomal dominant Emery- Dreifuss muscular dystrophy. Nat. Genet. 21, 285-288.

67. Fatkin, D., MacRae, C., Sasaki, T., Wolff, M.R., Porcu, M., Frenneaux, M., Atherton, J., Vidaillet, H.J., Jr., Spudich, S., De Girolami, U., Seidman, J.G., Seidman, C., Muntoni, F., Muehle, G., Johnson, W., and McDonough, B. (1999) Missense mutations in the rod domain of the lamin A/C gene as causes of dilated cardiomyopathy and conduction-system disease [see comments]. N. Engl. J. Med. 341, 1715-1724.

68. Muchir, A., Bonne, G., van der Kooi, A.J., van Meegen, M., Baas, F., Bolhuis, P.A., de Visser, M., and Schwartz, K. (2000) Identification of mutations in the gene encoding lamins A/C in autosomal dominant limb girdle muscular dystrophy with atrioventricular conduction disturbances (LGMD1B). Hum. Mol. Genet. 9, 1453-1459.

69. Cao, H. and Hegele, R.A. (2000) Nuclear lamin A/C R482Q mutation in canadian kindreds with dunnigantype familial partial lipodystrophy. Hum. Mol. Genet. 9, 109-112.

70. Shackleton, S., Lloyd, D.J., Jackson, S.N., Evans, R., Niermeijer, M.F., Singh, B.M., Schmidt, H., Brabant, G., Kumar, S., Durrington, P.N., Gregory, S., O'Rahilly, S., and Trembath, R.C. (2000) LMNA, encoding lamin A/C, is mutated in partial lipodystrophy. Nat. Genet. 24, 153-156.

71. De Sandre-Giovannoli, A., Chaouch, M., Kozlov, S., Vallat, J.M., Tazir, M., Kassouri, N., Szepetowski, P., Hammadouche, T., Vandenberghe, A., Stewart, C.L., Grid, D., and Levy, N. (2002) Homozygous defects in LMNA, encoding lamin A/C nuclear-envelope proteins, cause autosomal recessive axonal neuropathy in human (Charcot-Marie-Tooth disorder type 2) and mouse. Am. J. Hum. Genet. 70, 726-736.

72. Senior, A. and Gerace, L. (1988) Integral membrane proteins specific to the inner nuclear membrane and associated with the nuclear lamina. J. Cell Biol. 107, 2029-2036.

73. Broers, J.L., Machiels, B.M., van Eys, G.J., Kuijpers, H.J., Manders, E.M., van Driel, R., and Ramaekers, F.C. (1999) Dynamics of the nuclear lamina as monitored by GFP-tagged A-type lamins. J. Cell Sci. 112, 3463-3475.

74. Daigle, N., Beaudouin, J., Hartnell, L., Imreh, G., Hallberg, E., Lippincott-Schwartz, J., and Ellenberg, J. (2001) Nuclear pore complexes form immobile networks and have a very low turnover in live mammalian cells. J. Cell Biol. 154, 71-84.

75. Yang, L., Guan, T., and Gerace, L. (1997) Lamin-binding fragment of LAP2 inhibits increase in nuclear volume during the cell cycle and progression into S phase. J. Cell Biol. 139, 1077-1087.

76. Spann, T.P., Moir, R.D., Goldman, A.E., Stick, R., and Goldman, R.D. (1997) Disruption of nuclear lamin organization alters the distribution of replication factors and inhibits DNA synthesis. J. Cell Biol. 136, 1201-1212.

77. Bridger, J.M., Kill, I.R., O'Farrell, M., and Hutchison, C.J. (1993) Internal lamin structures within G1 nuclei of human dermal fibroblasts. J. Cell Sci. 104, 297-306.

78. Goldman, A.E., Moir, R.D., Montag-Lowy, M., Stewart, M., and Goldman, R.D. (1992) Pathway of incorporation of microinjected lamin A into the nuclear envelope. J. Cell Biol. 119, 725-735.

79. Pugh, G.E., Coates, P.J., Lane, E.B., Raymond, Y., and Quinlan, R.A. (1997) Distinct nuclear assembly pathways for lamins A and C lead to their increase during quiescence in Swiss 3 T3 cells. J. Cell Sci. 110, 2483-2493.

80. Lutz, R.J., Trujillo, M.A., Denham, K.S., Wenger, L., and Sinensky, M. (1992) Nucleoplasmic localization of prelamin A: implications for prenylation-dependent lamin A assembly into the nuclear lamina. Proc. Natl. Acad. Sci. U. S. A. 89, 3000-3004.

81. Sasseville, A.M.-J. and Raymond, Y. (1995) Lamin A precursor is localized to intranuclear foci. J. Cell Sci. 108, 273-285.

82. Izumi, M., Vaughan, O.A., Hutchison, C.J., and Gilbert, D.M. (2000) Head and/or CaaX domain deletions of lamin proteins disrupt preformed lamin A and C but not lamin B structure in mammalian cells. Mol. Biol. Cell 11, 4323-4337.

83. Lee, K.K., Gruenbaum, Y., Spann, P., Liu, J., and Wilson, K.L. (2000) C. elegans nuclear envelope proteins emerin, MAN1, lamin, and nucleoporins reveal unique timing of nuclear envelope breakdown during mitosis. Mol. Biol. Cell 11, 3089-3099.

84. Aitchison, J.D. and Rout, M.P. (2002) A tense time for the nuclear envelope. Cell 108, 301-304.

85. Gonczy, P. (2002) Nuclear envelope: torn apart at mitosis. Curr. Biol. 12, R242-244.

86. Beaudouin, J., Gerlich, D., Daigle, N., Eils, R., and Ellenberg, J. (2002) Nuclear envelope breakdown proceeds by microtubule-induced tearing of the lamina. Cell 108, 83-96.

87. Georgatos, S.D., Pyrpasopoulou, A., and Theodoropoulos, P.A. (1997) Nuclear envelope breakdown in mammalian cells involves stepwise lamina disassembly and microtubule-drive deformation of the nuclear membrane. J. Cell Sci. 110, 2129-2140.

88. Salina, D., Bodoor, K., Eckley, D.M., Schroer, T.A., Rattner, J.B., and Burke, B. (2002) Cytoplasmic dynein as a facilitator of nuclear envelope breakdown. Cell 108, 97-107.

89. Terasaki, M., Campagnola, P., Rolls, M.M., Stein, P.A., Ellenberg, J., Hinkle, B., and Slepchenko, B. (2001) A new model for nuclear envelope breakdown. Mol. Biol. Cell 12, 503-510.

90. Kiseleva, E., Rutherford, S., Cotter, L.M., Allen, T.D., and Goldberg, M.W. (2001) Steps of nuclear pore 
complex disassembly and reassembly during mitosis in early Drosophila embryos. J. Cell Sci. 114, 36073618 .

91. Collas, P. (1998) Nuclear envelope disassembly in mitotic extract requires functional nuclear pores and a nuclear lamina. J. Cell Sci. 111, 1293-1303.

92. Pines, J. and Hunter, T. (1991) Human cyclins A and B1 are differentially located in the cell and undergo cell cycle-dependent nuclear transport. J. Cell Biol. 115, 1-17.

93. Foisner, R. (1997) Dynamic organisation of intermediate filaments and associated proteins during the cell cycle. BioEssays 19, 297-305.

94. Heald, R. and McKeon, F. (1990) Mutations of phosphorylation sites in lamin A that prevent nuclear lamina disassembly in mitosis. Cell 61, 579-589.

95. Nikolakaki, E., Meier, J., Simos, G., Georgatos, S.D., and Giannakouros, T. (1997) Mitotic phosphorylation of the lamin B receptor by a serine/arginine kinase and p34(cdc2). J. Biol. Chem. 272, 6208-6213.

96. Courvalin, J.C., Segil, N., Blobel, G., and Worman, H.J. (1992) The lamin B receptor of the inner nuclear membrane undergoes mitosis- specific phosphorylation and is a substrate for p34cdc2-type protein kinase. J. Biol. Chem. 267, 19035-19038.

97. Ellenberg, J., Siggia, E.D., Moreira, J.E., Smith, C.L., Presley, J.F., Worman, H.J., and LippincottSchwartz, J. (1997) Nuclear membrane dynamics and reassembly in living cells: targeting of an inner nuclear membrane protein in interphase and mitosis. J. Cell Biol. 138, 1193-1206.

98. Yang, L., Guan, T., and Gerace, L. (1997) Integral membrane proteins of the nuclear envelope are dispersed throughout the endoplasmic reticulum during mitosis. J. Cell Biol. 137, 1199-1210.

99. Maison, C., Horstmann, H., and Georgatos, S.D. (1993) Regulated docking of nuclear membrane vesicles to vimentin filaments during mitosis. J. Cell Biol. 123, 1491-1505.

100. Buendia, B. and Courvalin, J.C. (1997) Domain-specific disassembly and reassembly of nuclear membranes during mitosis. Exp. Cell Res. 230, 133-144.

101. Collas, I. and Courvalin, J.C. (2000) Sorting nuclear membrane proteins at mitosis. Trends Cell Biol. 10, 58 .

102. Collas, P. and Poccia, D. (1996) Distinct egg membrane vesicles differing in binding and fusion properties contribute to sea urchin male pronuclear envelopes formed in vitro. J. Cell Sci. 109, 1275-1283.

103. Drummond, S., Ferrigno, P., Lyon, C., Murphy, J., Goldberg, M., Allen, T., Smythe, C., and Hutchison, C.J. (1999) Temporal differences in the appearance of NEP-B78 and an LBR-like protein during Xenopus nuclear envelope reassembly reflect the ordered recruitment of functionally discrete vesicle types. $J$. Cell Biol. 144, 225-240.

104. Vigers, G.P. and Lohka, M.J. (1991) A distinct vesicle population targets membranes and pore complexes to the nuclear envelope in Xenopus eggs. J. Cell Biol. 112, 545-556.

105. Glass, J.R. and Gerace, L. (1990) Lamins A and C bind and assemble at the surface of mitotic chromosomes. J. Cell Biol. 111, 1047-1057.

106. Glass, C.A., Glass, J.R., Taniura, H., Hasel, K.W., Blevitt, J.M., and Gerace, L. (1993) The alpha-helical rod domain of human lamins $A$ and $C$ contains a chromatin binding site. EMBO J. 12, 4413-4424.

107. Goldberg, M., Harel, A., Brandeis, M., Rechsteiner, T., Richmond, T.J., Weiss, A.M., and Gruenbaum, Y. (1999) The tail domain of lamin Dm0 binds histones H2A and H2B. Proc. Natl. Acad. Sci. U. S. A. 96, 2852-2857.

108. Taniura, H., Glass, C., and Gerace, L. (1995) A chromatin binding site in the tail domain of nuclear lamins that interacts with core histones. J. Cell Biol. 131, 33-44.

109. Duband-Goulet, I. and Courvalin, J.C. (2000) Inner nuclear membrane protein LBR preferentially interacts with DNA secondary structures and nucleosomal linker. Biochemistry 39, 6483-6488.

110. Ye, Q., Callebaut, I., Pezhman, A., Courvalin, J.C., and Worman, H.J. (1997) Domain-specific interactions of human HP1-type chromodomain proteins and inner nuclear membrane protein LBR. J. Biol. Chem. 272, 14983-14989.

111. Ye, Q. and Worman, H.J. (1996) Interaction between an integral protein of the nuclear envelope inner membrane and human chromodomain proteins homologous to Drosophila HP1. J. Biol. Chem. 271, 1465314656.

112. Polioudaki, H., Kourmouli, N., Drosou, V., Bakou, A., Theodoropoulos, P.A., Singh, P.B., Giannakouros, T., and Georgatos, S.D. (2001) Histones H3/H4 form a tight complex with the inner nuclear membrane protein LBR and heterochromatin protein 1. EMBO Rep 2, 920-925.

113. Kourmouli, N., Theodoropoulos, P.A., Dialynas, G., Bakou, A., Politou, A.S., Cowell, I.G., Singh, P.B., and Georgatos, S.D. (2000) Dynamic associations of heterochromatin protein 1 with the nuclear envelope. EMBO J. 19, 6558-6568.

114. Martins, S.B., Eide, T., Steen, R.L., Jahnsen, T., Skalhegg, B.S., and Collas, P. (2000) HA95 is a protein of the chromatin and nuclear matrix regulating nuclear envelope dynamics. J. Cell Sci. 113(Pt 21), 37033713.

115. Furukawa, K. (1999) LAP2 binding protein 1 (L2BP1/BAF) is a candidate mediator of LAP2- chromatin interaction. J. Cell Sci. 112, 2485-2492. 
116. Shumaker, D.K., Lee, K.K., Tanhehco, Y.C., Craigie, R., and Wilson, K.L. (2001) LAP2 binds to BAFDNA complexes: requirement for the LEM domain and modulation by variable regions. EMBO J. 20, 1754-1764.

117. Cai, M., Huang, Y., Zheng, R., Wei, S.Q., Ghirlando, R., Lee, M.S., Craigie, R., Gronenborn, A.M., and Clore, G.M. (1998) Solution structure of the cellular factor BAF responsible for protecting retroviral DNA from autointegration. Nat. Struct. Biol. 5, 903-909.

118. Zheng, R., Ghirlando, R., Lee, M.S., Mizuuchi, K., Krause, M., and Craigie, R. (2000) Barrier-toautointegration factor (BAF) bridges DNA in a discrete, higher-order nucleoprotein complex. Proc. Natl. Acad. Sci. U. S. A. 97, 8997-9002.

119. Furukawa, K., Glass, C., and Kondo, T. (1997) Characterization of the chromatin binding activity of lamina-associated polypeptide (LAP) 2. Biochem. Biophys. Res. Commun. 238, 240-246.

120. Vlcek, S., Korbei, B., and Foisner, R. (2002) Distinct functions of the unique C-terminus of LAP2alpha in cell proliferation and nuclear assembly. J. Biol. Chem. 277, 18898-18907.

121. Vlcek, S., Just, H., Dechat, T., and Foisner, R. (1999) Functional diversity of LAP2alpha and LAP2beta in postmitotic chromosome association is caused by an alpha-specific nuclear targeting domain. EMBO J. 18, 6370-6384.

122. Haraguchi, T., Koujin, T., Hayakawa, T., Kaneda, T., Tsutsumi, C., Imamoto, N., Akazawa, C., Sukegawa, J., Yoneda, Y., and Hiraoka, Y. (2000) Live fluorescence imaging reveals early recruitment of emerin, LBR, RanBP2, and Nup153 to reforming functional nuclear envelopes. J. Cell Sci. 113, 779-794.

123. Bodoor, K., Shaikh, S., Salina, D., Raharjo, W.H., Bastos, R., Lohka, M., and Burke, B. (1999) Sequential recruitment of NPC proteins to the nuclear periphery at the end of mitosis. J. Cell Sci. 112, 2253-2264.

124. Dabauvalle, M.C., Muller, E., Ewald, A., Kress, W., Krohne, G., and Muller, C.R. (1999) Distribution of emerin during the cell cycle. Eur. J. Cell Biol. 78, 749-756.

125. Haraguchi, T., Koujin, T., Segura-Totten, M., Lee, K.K., Matsuoka, Y., Yoneda, Y., Wilson, K.L., and Hiraoka, Y. (2001) BAF is required for emerin assembly into the reforming nuclear envelope. J. Cell Sci. 114, 4575-4585.

126. Segura-Totten, M., Kowalski, A.K., Craigie, R., and Wilson, K.L. (2002) Barrier-to-autointegration factor: major roles in chromatin decondensation and nuclear assembly. J. Cell Biol., in press.

127. Gant, T.M., Harris, C.A., and Wilson, K.L. (1999) Roles of LAP2 Proteins in nuclear assembly and DNA replication: truncated LAP2beta proteins alter lamina assembly, envelope formation, nuclear size, and DNA replication efficiency in Xenopus laevis extracts. J. Cell Biol. 144, 1083-1096.

128. Pyrpasopoulou, A., Meier, J., Maison, C., Simos, G., and Georgatos, S.D. (1996) The lamin B receptor (LBR) provides essential chromatin docking sites at the nuclear envelope. EMBO J. 15, 7108-7119.

129. Collas, P., Courvalin, J.C., and Poccia, D. (1996) Targeting of membranes to sea urchin sperm chromatin is mediated by a lamin B receptor-like integral membrane protein. J. Cell Biol. 135, 1715-1725.

130. Lourim, D. and Krohne, G. (1994) Lamin-dependent nuclear envelope reassembly following mitosis. Trends Cell Biol 4, 324-318.

131. Meier, J., Campbell, K.H., Ford, C.C., Stick, R., and Hutchison, C.J. (1991) The role of lamin LIII in nuclear assembly and DNA replication, in cell- free extracts of Xenopus eggs. J. Cell Sci. 98, 271-279.

132. Burke, B. and Gerace, L. (1986) A cell free system to study reassembly of the nuclear envelope at the end of mitosis. Cell 44, 639-652.

133. Dabauvalle, M.C., Loos, K., Merkert, H., and Scheer, U. (1991) Spontaneous assembly of pore complexcontaining membranes ("annulate lamellae") in Xenopus egg extract in the absence of chromatin. J. Cell Biol. 112, 1073-1082.

134. Ulitzur, N., Harel, A., Feinstein, N., and Gruenbaum, Y. (1992) Lamin activity is essential for nuclear envelope assembly in a Drosophila embryo cell-free extract. J. Cell Biol. 119, 17-25.

135. Lopez-Soler, R.I., Moir, R.D., Spann, T.P., Stick, R., and Goldman, R.D. (2001) A role for nuclear lamins in nuclear envelope assembly. J. Cell Biol. 154, 61-70.

136. Burke, B. (2001) Lamins and apoptosis: a two-way street? J. Cell Biol. 153, F5-7.

137. Steen, R.L. and Collas, P. (2001) Mistargeting of B-type lamins at the end of mitosis: implications on cell survival and regulation of lamins A/C expression. J. Cell Biol. 153, 621-626.

138. Goldberg, M.W., Wiese, C., Allen, T.D., and Wilson, K.L. (1997) Dimples, pores, star-rings, and thin rings on growing nuclear envelopes: evidence for structural intermediates in nuclear pore complex assembly. $J$. Cell Sci. 110, 409-420.

139. Walther, T.C., Fornerod, M., Pickersgill, H., Goldberg, M., Allen, T.D., and Mattaj, I.W. (2001) The nucleoporin Nup153 is required for nuclear pore basket formation, nuclear pore complex anchoring and import of a subset of nuclear proteins. EMBO J. 20, 5703-5714.

140. Smythe, C., Jenkins, H.E., and Hutchison, C.J. (2000) Incorporation of the nuclear pore basket protein Nup153 into nuclear pore structures is dependent upon lamina assembly: evidence from cell-free extracts of Xenopus eggs. EMBO J. 19, 3918-3931.

141. Sukegawa, J. and Blobel, G. (1993) A nuclear pore complex protein that contains zinc finger motifs, binds DNA, and faces the nucleoplasm. Cell 72, 29-38. 
142. Ottaviano, Y. and Gerace, L. (1985) Phosphorylation of the nuclear lamins during interphase and mitosis. $J$. Biol. Chem. 260, 624-632.

143. Appelbaum, J., Blobel, G., and Georgatos, S.D. (1990) In vivo phosphorylation of the lamin B receptor. Binding of lamin B to its nuclear membrane receptor is affected by phosphorylation. J. Biol. Chem. 265, 4181-4184.

144. Nikolakaki, E., Simos, G., Georgatos, S.D., and Giannakouros, T. (1996) A nuclear envelope-associated kinase phosphorylates arginine-serine motifs and modulates interactions between the lamin B receptor and other nuclear proteins. J. Biol. Chem. 271, 8365-8372.

145. Macaulay, C., Meier, E., and Forbes, D.J. (1995) Differential mitotic phosphorylation of proteins of the nuclear pore complex. J. Biol. Chem. 270, 254-262.

146. Favreau, C., Worman, H.J., Wozniak, R.W., Frappier, T., and Courvalin, J.C. (1996) Cell cycle-dependent phosphorylation of nucleoporins and nuclear pore membrane protein Gp210. Biochemistry 35, 8035-8044.

147. Ward, G.E. and Kirschner, M.W. (1990) Identification of cell cycle-regulated phosphorylation sites on nuclear lamin C. Cell 61, 561-577.

148. Peter, M., Nakagawa, J., Doree, M., Labbe, J.C., and Nigg, E.A. (1990) In vitro disassembly of the nuclear lamina and $\mathrm{M}$ phase-specific phosphorylation of lamins by cdc2 kinase. Cell 61, 591-602.

149. Peter, M., Heitlinger, E., Haner, M., Aebi, U., and Nigg, E.A. (1991) Disassembly of in vitro formed lamin head-to-tail polymers by CDC2 kinase. EMBO J. 10, 1535-1544.

150. Enoch, T., Peter, M., Nurse, P., and Nigg, E.A. (1991) p34cdc2 acts as a lamin kinase in fission yeast. $J$. Cell Biol. 112, 797-807.

151. Luscher, B., Brizuela, L., Beach, D., and Eisenman, R.N. (1991) A role for the p34cdc2 kinase and phosphatases in the regulation of phosphorylation and disassembly of lamin B2 during the cell cycle. EMBO J. 10, 865-875.

152. Goss, V.L., Hocevar, B.A., Thompson, L.J., Stratton, C.A., Burns, D.J., and Fields, A.P. (1994) Identification of nuclear beta II protein kinase C as a mitotic lamin kinase. J. Biol. Chem. 269, 1907419080.

153. Collas, P. (1999) Sequential PKC- and Cdc2-mediated phosphorylation events elicit zebrafish nuclear envelope disassembly. J. Cell Sci. 112, 977-987.

154. Thompson, L.J., Bollen, M., and Fields, A.P. (1997) Identification of protein phosphatase 1 as a mitotic lamin phosphatase. J. Biol. Chem. 272, 29693-29697.

155. Steen, R.L., Martins, S.B., Tasken, K., and Collas, P. (2000) Recruitment of protein phosphatase 1 to the nuclear envelope by A-kinase anchoring protein AKAP149 is a prerequisite for nuclear lamina assembly. $J$. Cell Biol. 150, 1251-1262.

156. Newport, J. and Dunphy, W. (1992) Characterization of the membrane binding and fusion events during nuclear envelope assembly using purified components. J. Cell Biol. 116, 295-306.

157. Boman, A.L., Delannoy, M.R., and Wilson, K.L. (1992) GTP hydrolysis is required for vesicle fusion during nuclear envelope assembly in vitro. J. Cell Biol. 116, 281-294.

158. Hetzer, M., Bilbao-Cortes, D., Walther, T.C., Gruss, O.J., and Mattaj, I.W. (2000) GTP hydrolysis by Ran is required for nuclear envelope assembly. Mol Cell 5, 1013-1024.

159. Zhang, C. and Clarke, P.R. (2000) Chromatin-independent nuclear envelope assembly induced by Ran GTPase in Xenopus egg extracts. Science 288, 1429-1432.

160. Bamba, C., Bobinnec, Y., Fukuda, M., and Nishida, E. (2002) The GTPase Ran regulates chromosome positioning and nuclear envelope assembly in vivo. Curr. Biol. 12, 503-507.

161. Gorlich, D. and Kutay, U. (1999) Transport between the cell nucleus and the cytoplasm. Annu. Rev. Cell Dev. Biol. 15, 607-660.

162. Mattaj, I.W. and Englmeier, L. (1998) Nucleocytoplasmic transport: the soluble phase. Annu. Rev. Biochem. 67, 265-306.

163. Zhang, C., Hutchins, J.R., Muhlhausser, P., Kutay, U., and Clarke, P.R. (2002) Role of importin-beta in the control of nuclear envelope assembly by Ran. Curr. Biol. 12, 498-502.

164. Wiese, C., Wilde, A., Moore, M.S., Adam, S.A., Merdes, A., and Zheng, Y. (2001) Role of importin-beta in coupling Ran to downstream targets in microtubule assembly. Science 291, 653-656.

165. Nachury, M.V., Maresca, T.J., Salmon, W.C., Waterman-Storer, C.M., Heald, R., and Weis, K. (2001) Importin beta is a mitotic target of the small GTPase Ran in spindle assembly. Cell 104, 95-106.

166. Gruss, O.J., Carazo-Salas, R.E., Schatz, C.A., Guarguaglini, G., Kast, J., Wilm, M., Le Bot, N., Vernos, I., Karsenti, E., and Mattaj, I.W. (2001) Ran induces spindle assembly by reversing the inhibitory effect of importin alpha on TPX2 activity. Cell 104, 83-93.

167. Timinszky, G., Tirian, L., Nagy, F.T., Toth, G., Perczel, A., Kiss-Laszlo, Z., Boros, I., Clarke, P.R., and Szabad, J. (2002) The importin-beta P446L dominant-negative mutant protein loses RanGTP binding ability and blocks the formation of intact nuclear envelope. J. Cell Sci. 115, 1675-1687.

168. Hetzer, M., Meyer, H.H., Walther, T.C., Bilbao-Cortes, D., Warren, G., and Mattaj, I.W. (2001) Distinct AAA-ATPase p97 complexes function in discrete steps of nuclear assembly. Nat. Cell Biol. 3, 1086-1091. 
169. Nili, E., Cojocaru, G.S., Kalma, Y., Ginsberg, D., Copeland, N.G., Gilbert, D.J., Jenkins, N.A., Berger, R., Shaklai, S., Amariglio, N., Brok-Simoni, F., Simon, A.J., and Rechavi, G. (2001) Nuclear membrane protein LAP2beta mediates transcriptional repression alone and together with its binding partner GCL (germ-cell-less). J. Cell Sci. 114, 3297-3307.

This article should be referenced as follows:

Foisner, R. (2003) Cell cycle dynamics of the nuclear envelope. TheScientificWorldJOURNAL 3, 1-20.

\section{Handling Editor:}

E. Nigg, Principal Editor for Cell Cycle - a domain of TheScientificWorldJOURNAL. 

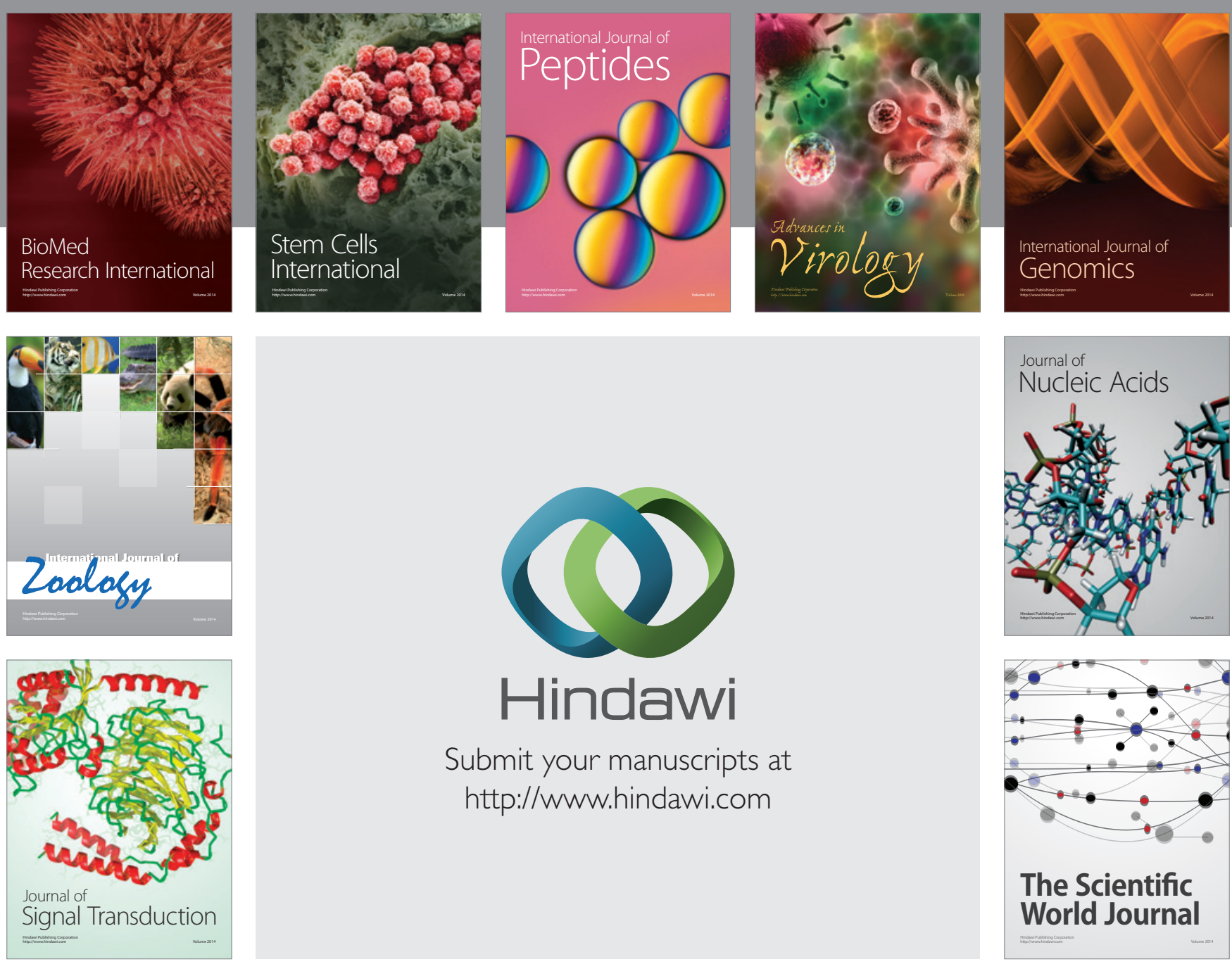

Submit your manuscripts at

http://www.hindawi.com
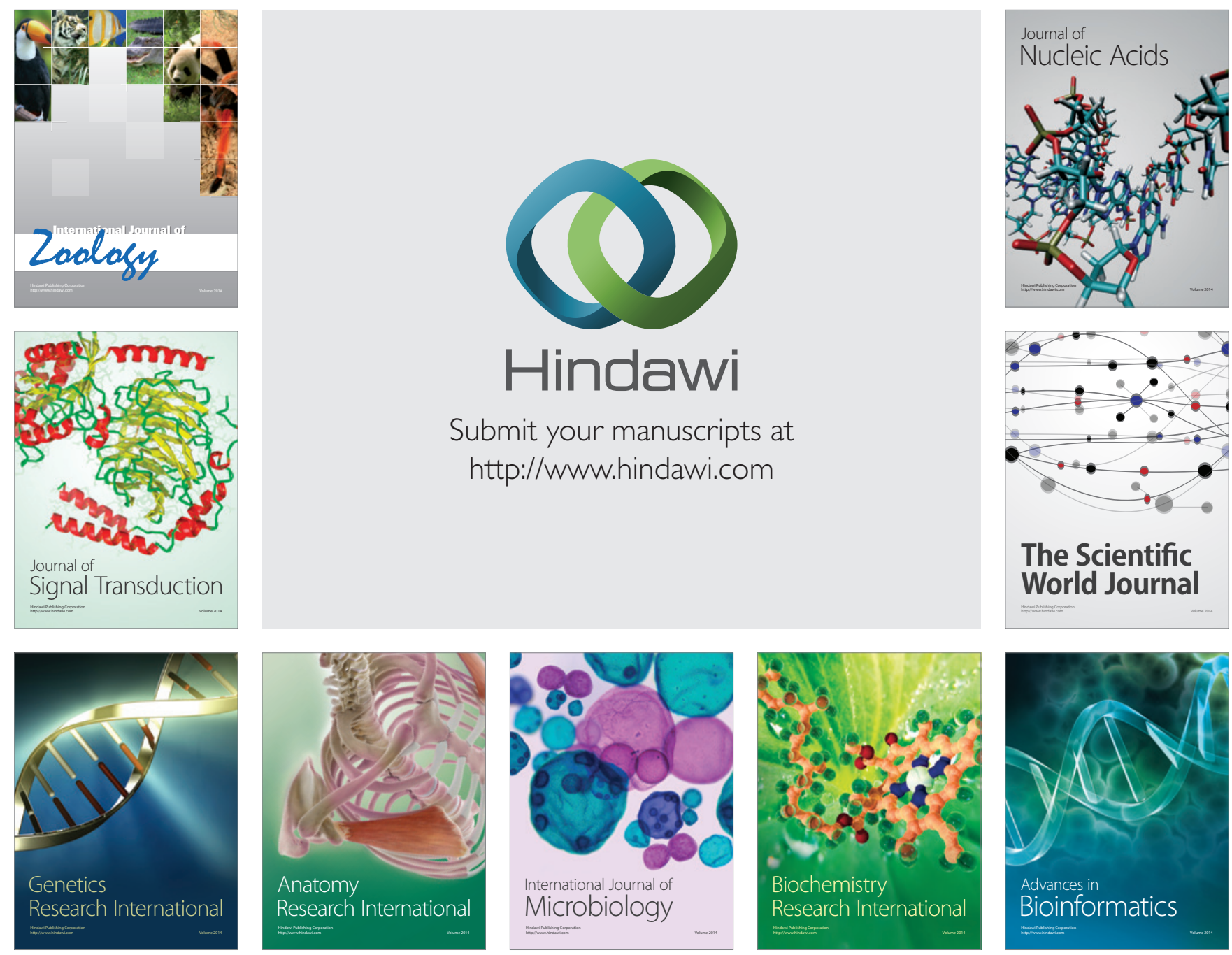

The Scientific World Journal
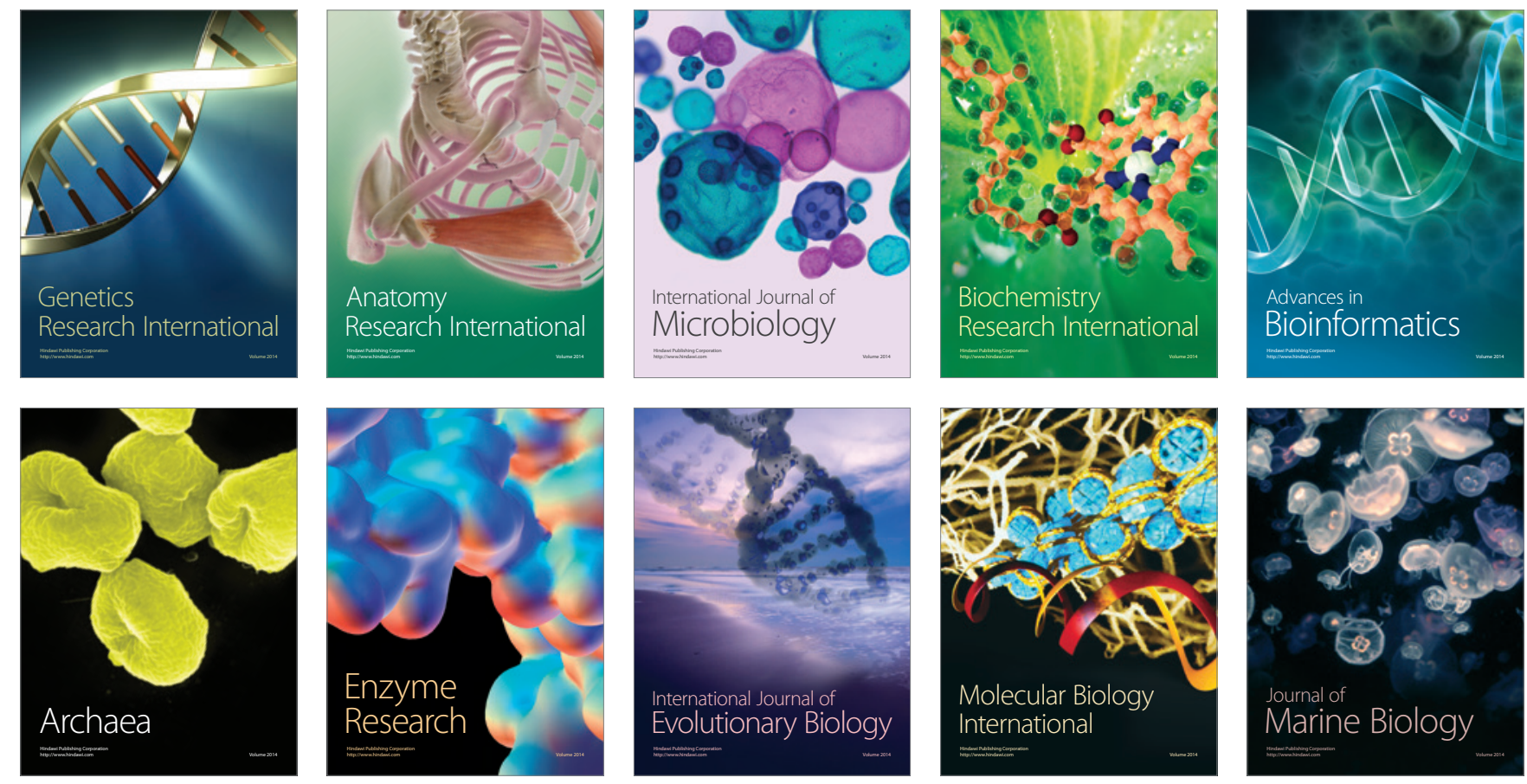